\title{
LA REPRESENTACIÓN Y LA MIRADA: RETRATO PICTÓRICO Y FALSA IDENTIDAD EN EL CINE NEGRO NORTEAMERICANO DE LOS AÑOS CUARENTA
}

\section{THE REPRESENTATION AND THE GAZE: PICTORIAL PORTRAIT AND FALSE IDENTITY IN 1940 S AMERICAN FILM NOIR}

\author{
Carlos A. Cúllar Alejandro \\ Universitat de València
}

\section{RESUMEN}

Este artículo analiza dos películas estadounidenses pertenecientes al modelo de Cine Clásico e inscritas en el género del Cine Negro. En ellas, el retrato pictórico de una mujer sirve de metáfora de la distorsionada mirada heterosexual masculina que victimiza tanto a hombres como a mujeres. Mi intención es defender la idea de que, lejos de la estereotipada imagen que tenemos sobre el cine normativo, la perspectiva actual nos permite afirmar que el Cine Clásico también produjo películas donde se criticaban los vicios de la mirada patriarcal sobre la mujer como objeto idealizado de deseo.

Palabras clave: Cine Clásico, retrato, Cine Negro, mujer, feminismo.

\begin{abstract}
This article analyses two American films pertaining to the Classical Film noir genre.

In those movies the pictorial portrait of a woman acts as a metaphor about distorted heterosexual male gaze that victimizes both men and women. My intention is to prove that far from our stereotypical image of normative cinema, a current perspective allows to state that Classical Cinema also produced films that denounced patriarchal gaze vices on women as an idealized object of desire.
\end{abstract}

Keywords: Classical Cinema, Portrait, Film Noir, Woman, Feminism. 


\section{RESUM}

\section{La representació i la mirada: retrat pictòric i falsa identitat al $\mathrm{Ci}$ - nema Negre nord-americà dels anys quaranta}

Aquest article analitza dues pel.lícules estatunidenques pertanyents al model de Cinema Clàssic i inscrites en el gènere del Cine Negre. En ambdues, el retrat pictòric d'una dona serveix de metàfora de la distorsionada mirada heterosexual masculina que victimitza homes així com dones. La nostra intenció és defensar que, lluny de l'estereotipada imatge que tenim sobre el cine normatiu, la perspectiva actual ens permet afirmar que el Cinema Clàssic també produí pel.lícules on eren criticats els vicis de la mirada patriarcal sobre la dona en tant objecte de desig idealitzat.

Paraules clau: Cinema Clàssic, retrat, Cinema Negre, dona, feminisme. 
Como cine de género dentro del modelo clásico, el Cine Negro se caracteriza por una serie de elementos básicos y rasgos definitorios que funcionan como invariantes genéricas. La tipología de personajes estereotipados figura entre esas invariantes y el tipo de la mujer fatal es uno de los más importantes. Que los seres humanos (hombres y mujeres) sufrimos (aunque no de la misma manera) las desventajas que supone vivir en una sociedad patriarcal es, creo, indiscutible. Que el machismo y la misoginia de esta sociedad se han visto reforzados por el peso que la tradición judeocristiana y el Derecho Romano han ejercido sobre nuestra mentalidad y nuestras instituciones también está, en mi humilde opinión, fuera de duda. Y si bien parece lógico que una cultura patriarcal promueva el discurso masculino y dificulte o anule el femenino, las nuevas generaciones de la crítica feminista aplicada al cine han cuestionado seriamente (o, al menos, matizado) los postulados que esa misma crítica feminista defendió en sus primeras manifestaciones. Así, si en su día pioneras de la importancia de Laura Mulvey ${ }^{’}$ defendieron que el cine construía la representación de lo femenino para la satisfacción de la mirada masculina, años después analistas como Carol J. Clover $^{2}$ demostraron que la identificación del público cinematográfico con los personajes de las películas que consumen no atiende tanto al criterio de identificación entre identidad sexual e identidad de género como al 
criterio basado en la función narrativa de los personajes dentro del relato. Dicho de otro modo, si como espectadores y espectadoras de cine nos proyectamos metafóricamente en la pantalla y la usamos como espejo donde encontrar un posible reflejo, parece que podemos (de hecho, lo hacemos) proyectarnos tanto en personajes femeninos como en personajes masculinos, independientemente de que seamos hombres o mujeres. Necesaria en su día, la visión simplista de Laura Mulvey y sus seguidoras ha sido, afortunadamente, corregida por estudiosas y analistas que han sido conscientes de la complejidad del fenómeno.

El presente artículo plantea como objetivo el análisis de dos películas estadounidenses pertenecientes al modelo de Cine Clásico e inscritas en el género del Cine Negro. Mi intención con ello (y a tenor de los resultados) es defender la idea (si no demostrarla) de que, lejos de la visión estereotipada y reduccionista que tenemos de un cine normativo mal estudiado, nuestra perspectiva actual nos permite afirmar que el llamado Modo de Representación Institucional permitía la producción y comercialización de películas subversivas dentro del sistema patriarcal, en tanto en cuanto bajo la aparente construcción de lo femenino como producto de consumo atractivo para el espectador masculino, lo que de verdad se ofrecía era una clara crítica de esa misma mirada masculina (supuestamente dominante) que primero idealiza a la mujer (falseando su naturaleza real) para luego sentirse víctima de sus "ardides" y usarla como chivo expiatorio de sus propios errores de percepción. A pesar de las apariencias, películas como las que voy a comentar no están protagonizadas por femmes fatales sino por hombres estúpidos. No es la mujer la que engaña sino el hombre quien se siente fascinado y se engaña por falta de madurez emocional y conocimiento real de lo que es una mujer, y esta idea aparece de forma clara y explícita en el argumento de las dos películas seleccionadas. Por otro lado, la clave de ese auto-engaño está, en estos dos casos, en la paradoja metalingüística basada en la contradicción entre la construcción pictórica y la representación cinematográfica de los personajes femeninos. De hecho, la clave está en el concepto de retrato y su distanciamiento con respecto al producto real, al resultado. Dicho de otro modo, la inclusión de retratos pictóricos en ambos filmes denuncia el mito de la mujer fatal como un puro constructo mental masculino, una fantasía machista, precisamente porque ambas películas evidencian de forma explícita la abismal diferencia entre los retratos y las retratadas, y todo ello dentro de los supuestos límites ideológicos y morales del cine clásico norteamericano.

Mi perspectiva en este sentido procura seguir, una de las líneas señaladas en su día por Annette Kuhn: 
la crítica feminista de cine puede servir para recontextualizar, mediante la interpretación y el análisis textual, ejemplos de cine clásico al adecuarlos a la perspectiva feminista sobre la representación cinematográfica [...] De esta forma películas clásicas y comerciales pueden resultar transformadas por interpretaciones alternativas, e incluso llegar a adquirir un interés nuevo e inesperado para las feministas. ${ }^{3}$

Conviene recordar que, aunque el lenguaje nunca es inocente, sin embargo se usa a menudo inconscientemente o sometido a convenciones cuya vulneración puede provocar dificultades en el proceso de comunicación entre emisores y receptores. Así, en una actualidad como la nuestra, la de una época que ha sido definida por no pocos especialistas como posfeminista, el uso de vocablos como "masculino" y "femenino" no dejan de ser una trampa de la que es difícil librarse. Incluso conceptos tan aparentemente intocables y asumidos como "hombre" y "mujer" tienen cada vez menos sentido en una línea argumentativa donde existe la posibilidad de que se imponga poco a poco la teoría queer que, según los especialistas:

se opone a toda reivindicación de identidad, incluyendo la asignación de un sexo estable [...] Aunque la teoría queer se opone a aquellos que desean regular la identidad [...] no busca tan solo expandir la comunidad de activismo antihomofóbico, sino más bien insistir en que la sexualidad no se resume fácilmente ni se unifica a través de la categorización. ${ }^{4}$

Consciente de la complejidad del asunto y de la necesidad de hacerme entender por una mayoría amplia, usaré los términos "hombre" y "mujer" en su sentido tradicional (el patriarcal) y en el moderno (el feminista). Igualmente, partiré de dos postulados que interpretan los retratos humanos desde el punto de vista del pensamiento mágico-poético (retrato como doble psíquico de la persona retratada) y de las teorías psicoanalíticas (retrato como proyección de las pulsiones de la persona que lo observa), de manera que, establecida mi perspectiva metodológica, me veo ya libre de abordar directamente el asunto. 


\section{Laura (Otto Preminger, 1944)}

Ejemplo perfecto de cine clásico que con el tiempo se ha convertido en un "clásico" del cine, el guion (nominado en su día al Óscar) de este largometraje corrió a cargo de Jay Dratler, Samuel Hoffenstein y Betty Reinhardt, quienes adaptaron la novela homónima de Vera Caspary. Así pues, entre el equipo de guionistas había una mujer y la novela de la que parte el guion también está escrita por otra mujer, por consiguiente debe admitirse que en este caso concreto de película clásica el discurso femenino (no necesariamente el feminista) está presente, lo que resulta especialmente significativo para la hipótesis que pretendo defender.

"I shall never forget the weekend Laura died" ("Nunca olvidaré el fin de semana en el que murió Laura"), así se inicia el relato, con la voz acusmática de quien va a ejercer como uno de los narradores intradiegéticos de la película, el crítico y columnista Waldo Lydecker. De esta manera, la sorprendente primera noticia que nos da el filme es que su protagonista ha fallecido. En este sentido Laura usa una estrategia argumental ya presente en Ciudadano Kane (Citizen Kane, Orson Welles, 1941): la reconstrucción de la personalidad de un ser ausente a través de los testimonios de quienes lo conocieron. Así, el duro y guapo teniente de policía Mark McPherson -interpretado magníficamente por el varonil Dana Andrews, actor poco conocido hasta ese momento- interroga a Waldo Lydecker -un extraordinario Clifton Webb, cantante y bailarín teatral nominado al Óscar por esta interpretación-, esteta delicado, egocéntrico, pedante, inteligente, susceptible y celoso, descubridor de Laura, preceptor suyo y enamorado no correspondido; Shelby Carpenter -un magnífico Vincent Price que todavía no se había convertido en el astro del cine de terror que todo el mundo recuerda, atlético playboy, simpático y con pocos escrúpulos; y, por último, la sofisticada Ann Treadwell -encarnada por la respetada secundaria Judith Anderson, célebre por su papel de ama de llaves en Rebeca (Rebecca), dirigida por Alfred Hitchcock en 1940- cuya ambigüedad nos hace dudar quién puede ser realmente objeto de sus afectos.

Iniciada la investigación policial, la curiosidad natural del público cinematográfico es parcialmente satisfecha cuando el oficial encargado del caso ve por primera vez a Laura o, mejor dicho, el cuadro donde ésta aparece representada. Así, el retrato funciona como vicario del ser ausente, como doble, si no metafísico al menos emocional, recuperando parcial y metafóricamente la función que tenía en la escultura funeraria egipcia, ${ }^{5}$ cobrando

5 En las tumbas del Antiguo Egipto se colocaban esculturas que representaban al difunto o difunta que cobraban carácter animista al poder cobijar al Ba o espectro de la persona fallecida y retratada. Conviene recordar que en las creencias egipcias, la persona se componía de cinco cuerpos diferentes, de los cuales uno de ellos, el $\mathrm{Ba}$, se separaba del cuerpo físico en el mo- 
así una función mágico-religiosa que, descontextualizada en la psique de un policía estadounidense de los años cuarenta, se convierte en puro fetiche del que se enamora, pues conviene tener presente que el investigador no se fascina con Laura, sino con su retrato, es decir, con su "fantasma" en el sentido psicológico del mismo, como obsesión procedente de un pasado del que, curiosamente, nunca ha participado el oficial de policía. De la idealización (de un "objeto" de posesión ya imposible) a la mitificación sólo hay un paso.

La presencia del retrato domina buena parte de la película, hasta el punto de abrirla y cerrarla al constituir el fondo sobre el que se superponen los títulos de crédito iniciales y finales del filme. Así, se establece un paralelismo interdisciplinar, en el cine ocurre como en la pintura: si el cuadro es el marco de la película, también forma parte de su contenido. ${ }^{6}$ Emplazado en el departamento de Laura, el retrato sirve para hacerla presente en ausencia del personaje, al menos durante la primera parte de la película, donde cumple su función primordial. Cuando McPherson visita por vez primera el hogar de la difunta, Waldo le impreca "Look at that!" refiriéndose al cuadro. La respuesta del policía es lacónica ("Not bad") y nada parece anunciar en ella su posterior fascinación necrófila.

Por mediación del retrato y el encuadre del plano, el filme reúne a todos los personajes importantes implicados en la trama cuando el teniente McPherson convoca a Shelby, Waldo y Ann. Gracias al cuadro, entendemos cómo la obsesión originada en Waldo fructifica transmitiéndose, como por contagio, a Mack McPherson. Secuencia clave es aquella en la que el policía se queda sólo, de noche, en el apartamento de Laura, consumiendo alcohol mientras intenta esclarecer el misterio, interrumpiendo su labor para mirar impactado el retrato de Laura una y otra vez, incapaz de sustraerse a su magnetismo. Su obsesión parece lógica si consideramos que el personaje esconde un mundo interior complejo y, posiblemente, atormentado, ${ }^{7}$ y que sólo consigue mantener la apariencia de entereza gracias a que adiestra

mento de la muerte y volaba hacia la dimensión habitada por los dioses, pero podía regresar de vez en cuando para confortar a la momia, es decir, al cuerpo físico embalsamado.

6 La enmarcación también es o puede ser un arte que enriquezca, complete, ensalce o minusvalore al cuadro del que forma parte, como bien saben artistas, galeristas y demás profesionales.

7 Sería muy interesante lo que nos podría decir un psicoanalista que tuviera a este hombre como paciente. En todo caso, la naturaleza genérica del filme (Cine Negro) implica una ambigüedad y complejidad habitualmente ausentes del cine policíaco en general. 
su autocontrol con el juego infantil que tiene a menudo entre sus manos. Finalmente, el alcohol y el agotamiento le vencen y se duerme sentado junto al retrato. Lo que ocurre a continuación muy bien podría ser un sueño: Laura aparece viva y se dirige al policía. La imagen onírica era ya un recurso aceptado por el cine clásico para jugar con el público y mostrar acciones que la conclusión del sueño acaba desmintiendo (justo lo que ocurrirá, lo veremos, en La mujer del cuadro), pero en Laura el supuesto sueño no lo es, se trata de una inteligente estrategia narrativa para desorientar inicialmente al espectador o espectadora del filme ante la primera gran sorpresa de la película: Laura sigue viva, ${ }^{8}$ es otra la persona que ha sido, por error, asesinada en su lugar. El juego de substituciones va del cuadro a la víctima inocente por una confusión de identidades, como vicarios de la "aparecida". Finalmente y con toda lógica, la falsa muerta sólo ha generado un falso fantasma.

Lo interesante con respecto a la presencia del retrato en el filme es que a partir de ese momento despliega una función diferente, ya no es su doble artificial, su vicario, sino el doble ideal que delata tanto la imperfección del ser humano que ha tomado como modelo, como la enfermiza imaginación de los hombres capaces de obsesionarse por ella. Tal y como comentaron algunos críticos de la época, ${ }^{9}$ el teniente McPherson se decepciona ante la Laura de carne y hueso. En efecto, el retrato levantó expectativas que la retratada no es capaz de satisfacer, pues Laura es hermosa, sí, tanto como aparece en el cuadro (la fotografía del filme ya se encargará de demostrarlo repetidas veces y de diferentes maneras) pero, belleza aparte, Laura es una mujer normal, no una diosa, es un ser humano con sus cualidades y sus defectos, buena persona pero limitada, como cualquier otro ser vivo. Laura es real, no la fantasía desplegada por el policía tras escuchar los testimonios de los interrogados y embelesarse ante el magnífico retrato pictórico. En ambos casos, McPherson ha recibido un retrato indirecto de Laura. Lo que aparece ante sus ojos, y su experiencia a partir de ahora, ya no es un retrato sino Laura en persona, sin mediadores. Con todo, hay que reconocer que el policía supera su "decepción" y acepta a Laura tal cual es, quizás porque para él su belleza es lo más importante y, en esa cuestión, la modelo no desmerece con respecto al cuadro.

8 La remisión, por tanto, a la naturaleza del retrato pictórico en una película como Rebeca $(R e-$ becca, Alfred Hitchcock, 1940) carece a partir de este momento de sentido.

9 Así se recuerda en la entrevista que Peter Bogdanovich le hizo a Otto Preminger y que se incluye en BOGDANOVICH, Peter (2008): El director es la estrella (II), Madrid, T\&B Editores. 

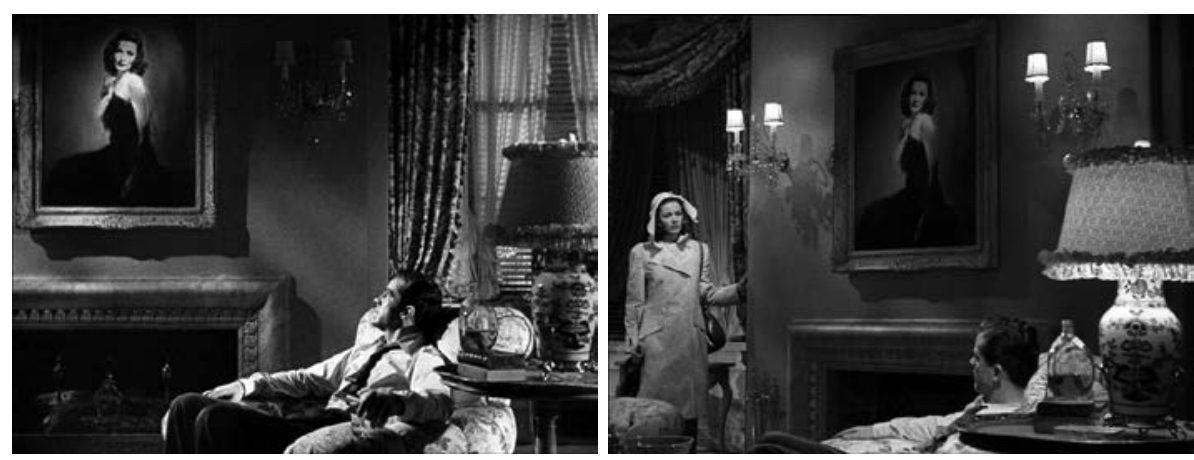

Figs.- 1 y 2. McPherson observa el lienzo, al lado del cual puede observarse, posteriormente a Laura.

La belleza del personaje de Laura es resultado de la materia prima (la hermosura de la propia actriz) transformada por el artista, por supuesto, es decir, por los profesionales del maquillaje, peluquería, vestuario y fotografía. En este sentido todo son virtudes en esta película. Su magnífica fotografía, premiada con un merecido Óscar, corrió a cargo de Joseph LaShelle, quien supo aplicar la estética expresionista propia del Cine Negro para crear la atmósfera adecuada y, además, supo iluminar objetos e intérpretes para destacar los elementos significativos de un esmeradamente cuidado decorado (los relojes de pared, especialmente) y realzar el magnetismo de Dana Andrews y Gene Tierney, sobre todo en los primeros planos que encuadran sus rostros, y es que Andrews es tan atractivo como Tierney. De hecho, si alguien considerase censurable que el criterio dominante en la pulsión masculina sea la belleza femenina, debería reflexionar sobre el hecho de que las mujeres presentes en el filme usen el mismo criterio que los hombres y sólo se sientan atraídas por los guapos de cuerpo atlético. Como suele ocurrir en la vida real, a los protagonistas no les da tiempo a conocerse realmente y su atracción deriva del poder primario del envoltorio.

Pero esta película no se conforma con denunciar una única variante de mirada patriarcal hacia las mujeres. El caso de Waldo es muy distinto al de McPherson y su fantasía nada tiene que ver con el citado retrato pictórico. De hecho, cuando muestra el cuadro al policía en la primera visita al apartamento de Laura, Waldo se queja de que el retratista nunca captó sus vibraciones, su calidez ("he never capted her vibrancy, her warmth"). La Laura de Waldo no es la del cuadro, es la que conoció personalmente y magnificó para luego reducirla a objeto de deseo. Y, en última instancia, a supuesto cadáver. Waldo es un Pigmalion que tras construir (pulir, perfec- 
cionar y promocionar) su mujer ideal se cree con el derecho de poseerla. Así, intenta eliminar de diferentes maneras la competencia de los sucesivos pretendientes de Laura, hasta que su impotencia ante la consciencia de su fracaso (Laura prefiere cualquier hombre de físico atlético y varonil antes que a su inteligente y sofisticado protector) le lleva a la típica reacción machista que conecta los conceptos de falso amor (celos) y reacción agresiva del objeto deseado (la mujer por él cosificada a la que cree amar). Un despechado Waldo intenta asesinar por dos veces a Laura. Las dos veces fracasa, la primera por confundirla con otra mujer, la segunda gracias a la eficaz actuación policial. Lo más significativo de la conclusión del filme no es que despeje el camino para una posible futura relación entre Laura y McPherson, sino que incide en lo que creo es uno de los mensajes fundamentales: la distorsión enfermiza de la realidad por parte de los hombres que se enamoran de las fantasías que construyen sobre mujeres reales. Waldo fallece, tras recibir los disparos de un agente de la ley, mientras declara su amor a Laura. Waldo muere creyendo todavía que la ama, cuando sólo sentía apego obsesivo hacia ella.

Una lectura alternativa del filme sería la que implica considerar al teniente de policía como doble simbólico de Laura (al fin y al cabo, ambos son morenos, ambos son bellos, ambos son emocionalmente co-dependientes), un doble invocado inconscientemente por Waldo si tenemos en cuenta la evidente naturaleza bisexual de este personaje. ${ }^{10} \mathrm{Si}$ fuera así, la cualidad de fetiche se transmitirá del personaje femenino al masculino, pero Laura debe morir pues mantenerla viva implica la imposible aceptación del ser deseado como andrógino "desdoblado" (dividido), por no hablar de la incapacidad de Waldo por asumir la ambivalencia de su libido." "De ser defendida esta hipótesis se pondrían sobre la mesa tres factores determinantes: la diferencia de género, la diferencia sexual y la sexualidad. Ello implicaría, supongo, activar simultáneamente la colaboración pacífica de la teoría feminista y de la teoría queer. Pero esta interpretación es, supongo, poco probable y, en todo caso, no la voy a desarrollar en este artículo. Tras el trágico clímax final de la película, el "The End" aparece impreso sobre un plano general del retrato de Laura, un objeto cuya justificación

10 Aunque no lo considero determinante, sí creo conveniente recordar la condición homosexual de Clifton Webb. Para más información al respecto remito, por ejemplo, a McLELLAN, Diana (2002), Greta \& Marlene. Safo va a Hollywood, Madrid, T\&B Editores.

11 A pesar de su cultura e inteligencia, Waldo es incapaz de invocar la fantasía alquímica. 



Figs.- 3 y 4 . Main title shot del filme y The End final, ambos inscritos sobre el cuerpo pintado de Laura.

diegética lo hace consecuencia de la atracción que esta mujer ejerce sobre los hombres que la conocen (recordemos que el retrato lo pinta uno de sus pretendientes, "retirado de circulación" por Waldo). Como tal, era importante que su calidad y sus cualidades legitimaran igualmente la reacción del policía ante el mismo. Cuando la película empezó a ser dirigida por Rouben Mamoulian, su esposa (que era pintora) realizó un retrato de Gene Tierney. Luego, cuando Darryl Zanuck (jefe de los estudios de la $20^{\text {th }}$ Century Fox) le encargó la dirección del proyecto a Otto Preminger, se descartó tanto el metraje rodado por Mamoulian como el cuadro pintado por la esposa de éste. Fue entonces cuando se decidió ampliar una fotografía de la actriz realizada por el fotógrafo del estudio Frank Poloni, quien la retocó con una capa de óleo y barniz para que pareciese una pintura.

A pesar de la desconfianza inicial por parte de la productora y de la reacción desigual de la crítica, el filme constituyó un gran éxito comercial que impulsó con fuerza la carrera de todos sus intérpretes y que con el tiempo ha acabado por ser considerado una de las obras maestras del Cine $\mathrm{Ne}$ gro norteamericano, éxito del que fue parcial responsable la banda sonora musical, dominada por el "leit-motiv" asociado al personaje protagonista, y compuesta por el entonces desconocido David Raksin. Del tema musical, que alcanzó gran popularidad en su época, se hicieron numerosas versiones y la propia película sufrió (nunca mejor dicho) varios "remakes", especialmente para el medio televisivo.

\section{La mujer del cuadro (The Woman in the Window, Fritz Lang, 1945)}

A partir de un guión de Nunnally Johnson inspirado en la novela Once Off Guard de J. H. Wallis, este filme constituye una inmensa broma al público -una burla del género del suspense a lo Hitchcock- cuando en el momento 
crítico del relato éste se desvela como un sueño del protagonista, desmantelando cualquier posible y esperada consecuencia negativa a causa de su conducta. En efecto, el astro del cine de "gangsters" Edward G. Robinson ${ }^{12}$ interpreta a Richard Wanley, un hombre equilibrado, agradable y respetable padre de familia (esa institución sagrada de la cultura judeocristiana occidental, especialmente americana) que trabaja como docente universitario, ${ }^{13}$ en suma, Richard Wanley es, en apariencia, un ciudadano modélico. Pero la tranquila normalidad va a ser pronto asaltada por un inesperado desencadenante de la tragedia.

Tras una amistosa charla con sus amigos (el Dr. Barkstane y el fiscal Frank Lalor, interpretado este último por el siempre competente actor secundario Raymond Massey), Wanley se detiene ante un escaparate que muestra el retrato de una atractiva y misteriosa mujer descubriendo, para su sorpresa y la nuestra, que la retratada está a su lado, pues la mujer gusta de acudir al lugar para poder observar las reacciones de quienes se detienen a admirar el cuadro. Retrato y retratada comparten plano gracias al reflejo de la segunda sobre el escaparate que protege al primero. ${ }^{14}$ Alice Red, que así se llama la joven interpretada por Joan Bennett, invita a Wanley a su casa. Una vez allí, son sorprendidos por el amante de Alice que, en un ataque de celos, intenta estrangular a Wanley. Con la ayuda de Alice, el profesor salva la vida al matar en defensa propia a su atacante. Tras superar serias dudas, deciden deshacerse del cadáver para no verse implicados en el trágico suceso. En el traslado del cuerpo, el inexperto Wanley comete todas las torpezas posibles imaginables (recurso perfectamente orquestado por Lang para provocar ansiedad en su público) dejando numerosas pistas. De regreso al hogar, su conciencia le impide descansar tranquilo y su sentimiento de culpabilidad le hace meterse él mismo en la boca del lobo cuando decide acompañar a su amigo, el fiscal Lalor, en la investigación del caso. Con todo, la policía no sospecha ni de él ni de Alice, pero una llamada de ésta última le pone en guardia sobre el chantaje al que Heidt (Dan Duryea, secundario asiduo al género), el antiguo guardaespaldas del fallecido, les está sometiendo. Wanley y Alice conciertan (esta vez sí) asesinar a Heidt, pero el plan fracasa. En Lang, como en Hitchcock, se subraya con frecuencia lo sencillo que es matar involuntariamente a alguien y lo difícil que resulta, en cambio, cuando se planea hacerlo.

12 Desde que alcanzara la fama en Hampa dorada (Little Caesar, Mervin Leroy, 1930).

13 Considerado en aquella época, lejana ya, como oficio digno e, incluso, prestigioso, al menos desde el punto de vista intelectual y social.

14 Y ello se hace posible de forma solvente gracias al director de fotografía de Milton Krasner. 


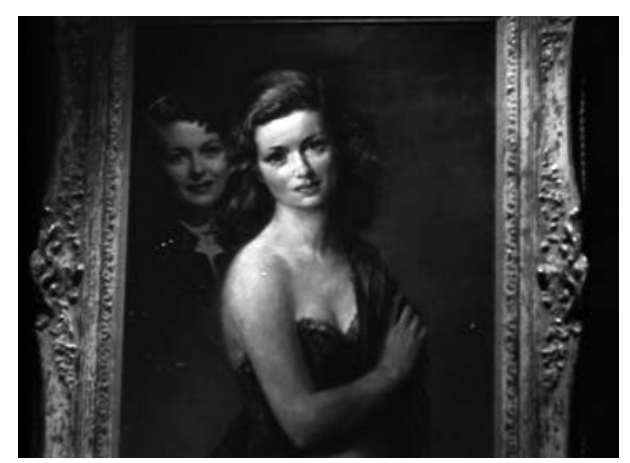

Fig.- 5. La representación pictórica de Alice Reed funde con el cuerpo de la misma reflejado en el escaparate.

Sintiéndose atrapado en una situación crítica de la que no sabe salir, Wanley decide suicidarse, inconsciente de que Heidt ha muerto en un tiroteo con la policía que, giro inesperado, le va a cargar con todas las culpas. Pero la verdadera sorpresa para el público de la época (y para el actual, si se ve por primera vez la película) viene con el giro argumental final que nos desvela que todo lo visionado ha sido un sueño -más bien una pesadillapor parte de Wanley, que se había quedado dormido en su club mientras leía tras la conversación con sus viejos amigos.

Las casualidades presentes en el argumento del filme nos remiten a tradiciones mitológicas como la de Pigmalión y Galatea, donde una obra de arte cobra vida, al menos en el momento en que el reflejo del escaparate que exhibe el cuadro funde su imagen con la de la modelo, que acude para ver la reacción de las personas que se detienen a mirar. Curiosa inversión ésta del concepto de "voyeur" -de quien mira sin ser visto- pues en este caso quienes se deleitan mirando el retrato ignoran que están siendo vistos por la retratada. No obstante, este detalle abre el nudo del relato y lo cierra construyendo un ingenioso gag que ayuda a eliminar totalmente la tensión acumulada: el cuadro visto a través del escaparate vuelve a ser contemplado por el protagonista, despierto ya y a salvo de todo peligro, pero su fruición le reserva un pequeño susto que amenaza con que lo soñado se vuelva realidad, construyendo así una supuesta estructura cíclica que, sin embargo, se ve de inmediato interrumpida, pues el nuevo reflejo que se funde con el retrato no es ya el de la retratada sino el de una mujer que le pide fuego para encender su cigarrillo.

El sueño como recurso narrativo y excusa argumental sirvió en su momento para sortear posibles problemas con la censura por parte de la producto- 
ra, pues Wanley no ha sido infiel a su esposa y su suicidio no es real ${ }^{15}$; para salvar al simpático protagonista de un destino trágico y posibilitar un "happy end" al no ser ya necesario un final compensatorio que le castigue, pues Wanley no ha matado a nadie; $y$, finalmente, para demostrar el origen inconsciente del poder que la mirada masculina despliega (muy a su pesar) ante la presencia de una imagen femenina tan irreal con respecto a su referente (la modelo) como el propio sueño con respecto a la vida real y consciente del protagonista, pues Wanley, por muy profesor universitario que sea, es, al fin y al cabo, un hombre. ${ }^{16}$

Pero si reflexionamos sobre esta película, en ella ni el retrato ni el reflejo onírico que devuelve el escaparate se corresponden con la imagen de una típica "mujer fatal" del Cine Negro, pues Alice no es sino es una víctima más de las circunstancias. Puede ser una mujer de comportamiento moral discutible pero no es malvada, no maneja a los hombres a su antojo, es maltratada por su amante y por el guardaespaldas, y se comporta de forma leal con un protagonista a quien nunca ha pretendido crearle problemas. En todo caso es el retrato y su incorrecta percepción ly no la retratada) el verdadero desencadenante de los problemas. No es la mujer fatal la diana moral de la película sino el hombre inmaduro que se fascina con la fantasía mental que crea su mirada. La mujer del cuadro es rica en temática (como ocurre con todas las películas dirigidas por Lang) pero por lo que respecta a la presencia y función del cuadro en la misma, el retrato pictórico es (gracias, precisamente, al título del filme) un enorme "Mac Guffin", algo aparentemente importante para los protagonistas que, sin embargo, configura una mera excusa argumental para desarrollar el relato tal y como le interesa a su guionista. En este sentido, el juego de espejos y de influencias mutuas entre Lang y Hitchcock se convierte en tema digno de una tesis doctoral. Pero si el cuadro es un Mac Guffin, la mujer que ha sido retratada en él también lo es, tal y como demuestra el recurso onírico para sacar a Wanley del atolladero en el que se había metido. Los sueños son una actividad mental del inconsciente y el sueño de Wanley es un producto

15 El Hollywood de la época, acosado por el llamado "Código Hays" -realmente redactado por el sacerdote católico Daniel Lord y el laico Martin Quigley- difícilmente hubiera admitido el suicidio del protagonista.

16 El recurso onírico también puede estar presente en Laura a partir del momento en que aparece el personaje, al menos en opinión de algunos especialistas: "Kristin Thompson dedicó un famoso ensayo a interpretar Laura como si esta secuencia y todo lo que la sigue, fuera un sueño del teniente" en FUJIWARA, Chris (2009), "Escena clave. El regreso. Laura", en FUJIWARA, Chris (ed.), Momentos clave. 100 años de cine, Barcelona, Blume, p. 147. 
de su libido reprimida, una fantasía desplegada por su inconsciente como vía de escape de una vida rutinaria, encorsetada y castrada por el peso del Yo y del Super Yo. El ego ("Das Ich") es la máscara, la personalidad oficial y pública que Wanley se ha construido para ser aceptado por el Super ego ("Das Über Ich"), y ambos son tan poderosos que ni siquiera permiten al ello ("Das Es") tomarse un respiro recreando una realidad paralela donde sus instintos y deseos puedan ser realizados. Es significativo que el sueño se convierta en pesadilla, la posibilidad de hacer lo que a Wanley le venga en gana (tener una aventura extramatrimonial $o$, al menos, tontear con una mujer atractiva) es frustrada incluso en una actividad, la onírica, que se supone libre y que no tiene por qué traer consecuencias visibles en el mundo real. ¡La estructura de la personalidad de Wanley está tan desequilibrada, a pesar de su apariencia de normalidad, que es capaz de autocensurar sus propios sueños! Lo problemático, precisamente, es que Wanley es un hombre normal, dicho de otro modo, que la normalidad institucionalizada hace a los seres humanos personas tan preocupadas por el juicio ajeno, por la valoración que puedan recibir del exterior, los hace tan dependientes de lo que los demás puedan opinar, tan sometidos al sistema, que se impiden ser ellas mismas incluso en aquellos reductos íntimos (los sueños) a los que nadie más tiene acceso. Un hombre sometido a esa insoportable presión (presión moral, presión social) tiende (o puede tender) a crear su fantasía de mujer y creer que la mujer real es como la que ha podido ver en un cuadro que le resulta atractivo. De nuevo, y como en el caso anterior, la película denuncia lo erróneo de la mirada masculina que puede construir o interpretar una imagen de lo femenino... y creérsela.

\section{INFIRIENDO CONCLUSIONES}

Cuando pensamos en el concepto de retrato parece que su carácter mimético sea una cualidad intrínseca y necesaria. De un retrato esperamos, incluso exigimos, que se parezca lo máximo posible al modelo que retrata. Sin embargo, la historia del arte ha demostrado una constante pugna lo quizás, convivencia) entre el realismo y la idealización del (o de la) modelo. Hemos querido ver idealización en el busto escultórico que retrata a Pericles (esculpido supuestamente por Krésilas hacia el 429 a.C.) aún cuando nadie sabe cómo era el rostro real del militar y político griego. Del mismo modo, queremos ver mayor realismo en los bustos romanos, quizás porque sabemos que muchos derlván de las mascarillas de cera mortuorias que hacían de sus difuntos, a los que luego veneraban. Pero żquién puede asegurar a ciencia cierta que el rostro de Pericles o el de la reina egipcia Nefertiti no eran como los de los famosos bustos escultóricos que los representan? 
Por lo general juzgamos un retrato usando como criterio básico la fidelidad con respecto a la persona retratada pero la historia de la pintura, incluso la del retrato fotográfico, nos ha demostrado que la fidelidad se reparte entre el mimetismo físico y el psicológico. En ocasiones, en un retrato ly su versión distorsionada y humorística, la caricatura) se reconoce mejor al retratado por el acierto en la representación de su personalidad que por los rasgos físicos. Si la personalidad es el conjunto de componentes que constituyen la individualidad de una persona, la persona es, en el fondo, un personaje ${ }_{17}^{17}$ pues todos los seres humanos tenemos una serie de subpersonalidades ${ }^{18}$ y un surtido de roles sociales que activamos o desactivamos (consciente e inconscientemente) según nuestras necesidades y conveniencias. Si a lo dicho añadimos que todo retrato es (o puede ser) un retrato parcial del retratista, es decir, una mixtura entre el modelo y el artista que proyecta su personalidad en su obra, entonces seremos conscientes de la extrema complejidad del tema que estamos tratando.

En todo caso, quiero hacer alusión a la esclarecedora etimología del término "retrato" para que luego pueda servirme de instrumento auxiliar en mi discurso. En latín, "retractus-a-um" significa alejado, retirado. Como verbo, "retracto" tiene el sentido de volver a coger, traer de nuevo, renovar. Por su parte, "portrait" (vocablo común en inglés y en francés) deriva del latín "protaho", con el sentido de sacar a la luz, poner de manifiesto. Con estos antecedentes etimológicos ${ }^{19}$, sabemos ya que los cuadros de género retratístico (como los que se encargan en la vida real, como los que están presentes en la diégesis de Laura y de La mujer del cuadrol ejercen una doble función: hacer presente a la persona ausente y poner de manifiesto su naturaleza sacando a la luz algo oculto.

En la definición que el patriarcado ha hecho de lo femenino y en el reparto de roles que le ha otorgado, una de las tendencias dominantes ha sido la idealización de la maternidad y, con ello, el de la mujer en su rol de madre, una idealización distinta, sin embargo, de la que realizó el

17 "Persona" es en su origen un vocablo del latín que hacía referencia a las máscaras usadas por los actores de teatro para incorporar a sus personajes.

18 Uso el término en el sentido en que lo aplicó la Psicosíntesis, introducida por el psiquiatra italiano Roberto Assagioli (1888-1974) y desarrollado luego por John Rowan en su estudio Subpersonalities: The People Inside Us, publicado en Londres por la editorial Routledge en el año 1990.

19 Remito, para la traducción al castellano de los términos latinos aludidos, a MIR, José M., Diccionario ilustrado latino-español español-latino, SPES, Barcelona, 1962. 
matriarcado. Por consiguiente, en una sociedad patriarcal, el hombre heterosexual tiende, por lo general, a idealizar a su madre y lo que se supone que ésta le ha aportado. Después, en su edad adulta, lejos de superar la lógica co-dependencia emocional y física hacia la mujer (la madre de su infancia), la proyecta (por consiguiente, la mantiene) en la mujer de quien espera que ejerza el rol de esposa o compañera. Esa visión idealizada es la que provoca una posterior decepción cuando la realidad se impone con el tiempo y el hombre descubre a la mujer como un ser humano (con sus cualidades y sus defectos) en lugar de la "diosa" polivalente que había imaginado. Esa decepción puede, según el carácter, perfil psicológico y educación recibida, provocar distintas reacciones (que no respuestas) en el hombre, entre ellas la reacción agresiva que lleva a ejercer la violencia física o psicológica contra la mujer a la que acaba responsabilizando de su sufrimiento emocional y convirtiendo en chivo expiatorio para así no tener que asumir su propia responsabilidad.

Las dos películas que he seleccionado muestran personajes masculinos víctimas de ese comportamiento, con la particularidad de que el motor desencadenante de la idealización desmedida que ejercen sobre la figura femenina resulta ser un retrato pictórico de la misma. La representación idealizada de una mujer siembra la fantasía masculina de un hombre emocionalmente inmaduro. Pero en estos filmes no son ellos (los hombres inmaduros con exceso de imaginación) los que luego ejercen la violencia contra estas mujeres reales (pues las virtuales nunca son dañadas, los retratos pictóricos sobreviven tras haber desaparecido el "hechizo"), sino otros hombres (igualmente inmaduros pero que esconden su miedo bajo una coraza de agresividad) capaces de inventarse una mujer y encapricharse de ella sin necesidad de cuadro alguno.

Ni Laura ni La mujer del cuadro construyen historias en torno a las actividades de una mujer fatal, aunque ambas películas pertenezcan al llamado Cine Negro. Lejos de adoptar perspectivas misóginas y machistas, ambas películas denuncian el artificio conceptual y muestran a la mujer como un ser humano normal cuya visión es distorsionada por hombres cuya psique y emociones se encuentran en conflicto. Como demuestran estas películas, el cine clásico estadounidense de los años cuarenta fue capaz de denunciar sutilmente el origen virtual de la fascinación masculina hacia las mujeres a las que la sociedad convertía en objeto de deseo, y haciendo responsable último de ello no a la mujer deseada sino a la inmadurez (la ingenuidad estúpida y fuera de lugar cuando se da en un adulto) del hombre que la idealiza. Con ello, los cuadros son retrato no tanto de las modelos que han posado como del sujeto masculino que ejerce la percepción estética cuando los observa. Dichos cuadros se convierten en lienzos donde el hombre 
proyecta su fantasía, su búsqueda utópica de algo que sólo existe en su mente. Traumas infantiles o adolescentes no resueltos generan cargas emocionales negativas que, si no han sido neutralizadas, provocan en el sujeto que las padece reacciones viscerales. En los filmes estudiados, los cuadros ofrecen una promesa que crea expectativas imposibles de ser satisfechas. Dichos cuadros, más que retratos de las retratadas, son espejos donde se reflejan los deseos de los hombres que miran. El discurso dominante en ambos filmes (el planteado por sus guionistas y directores) denuncia el discurso patriarcal (simbolizado por los retratos pictóricos) que representa a la mujer en su connotación mítica, y la prueba de que esto es así es la opción voluntaria de haber descartado la tipología de la "Femme Fatale" como encarnación por parte de las protagonistas femeninas de ambas películas. Al contrario, ambas mujeres son mostradas como víctimas de dicha mitificación. En este sentido, los cuadros son los estímulos visuales del doble invertido creado por la imaginación de los personajes masculinos. Los cuadros y su interpretación diegética son producto del discurso y la mirada masculinas, pero los discursos de las películas son en buena medida antipatriarcales por denunciar y condenar dichas interpretaciones. Es importante señalar que en ninguna de las dos películas ha sido el protagonista masculino el autor de los cuadros $^{20}$. Irónicamente, esta circunstancia enfatiza la condición de víctima de los hombres perjudicados por un sistema que en principio existe para asegurar su poder sobre las mujeres. Los hombres, en estos filmes, funcionan como metáfora de la gran mentira que el sistema educativo y la moral imperantes han vendido desde hace, por lo menos, tres siglos. Estas películas de los años cuarenta del pasado siglo XX nos prevenían ya sobre el peligro de esa mentira a través de sus consecuencias. Lo más terrible de todo es que, bien entrados ya en la segunda década del siglo XXI, parece que todavía no hemos aprendido la lección. Basta escuchar o leer las noticias cada día para comprobarlo.

Se me dirá que la lectura que he hecho de estas dos películas no coincide con la que la crítica y el público de los años cuarenta hicieron cuando se estrenaron. Seguramente sea así, sin embargo yo añadiría que en esa época tampoco nadie aplicó una lectura de género que desde una perspectiva feminista acusara al cine clásico de ser patriarcal ni a estas películas de ser machistas. En este sentido, me parece pertinente recurrir a una cita algo extensa para llegar a mi conclusión final. En uno de sus textos más importantes, Annette Kuhn afirmaba:

20 Al contrario de lo que ocurre en filmes como La chute de la maison Usher (Jean Epstein, 1928) y Jennie (Portrait of Jennie, William Dieterle, 1948), donde pintor y protagonista masculino se encarnan en un mismo personaje. 
Una vez que se adopta una concepción de la interpretación como práctica activa y comprometida, se vuelve redundante la distinción entre películas que contienen una autocrítica interna y películas que tienen una completa complicidad ideológica. Y ello porque a estas alturas el interés del análisis reside en el proceso de la interpretación tanto o más que en el texto mismo: si la interpretación es una actividad dinámica y comprometida, es posible afirmar que los textos se constituyen en y a través del acto de interpretación. Esto no quiere decir que todos los textos sean susceptibles de todo tipo de interpretaciones, sino más bien que los significados no están fijados y determinados para siempre en un texto-encerrados dentro de él a la espera de que los libere la interpretación-. La idea es más bien que los textos pueden transmitir una variedad de posibles significados y que es posible que puedan recibir interpretaciones diferentes en épocas y lugares distintos. Si esto es así, se vuelve difícil afirmar que ciertas películas y no otras presentan "rupturas" de modo inherente. ¿Quién puede juzgar qué películas sí y qué películas no? Quizás sea más acertado defender que se puede "desmontar", si es necesario, el funcionamiento ideológico de la mayor parte o de todas las películas del cine clásico por medio del análisis textual. ${ }^{21}$

De este modo, si la perspectiva feminista estuvo (y está) legitimada para etiquetar como patriarcal un discurso que nadie identificaba como tal en el momento en que se construyó, creo que un estudio desde una de las perspectivas de género vigentes hoy día, está igualmente legitimada para calificar de feminista una variante del cine clásico que tampoco fue considerado como tal ni en su época ni en el periodo en el que otras generaciones feministas lo estudiaron. $Y$ es que una institución inconsciente de ser patriarcal ¿̇podía acaso estar capacitada para identificar los productos feministas que ella misma generaba? Como se puede comprobar, el uso de etiquetas, juicios de valor y generalizaciones es tan arriesgado como meterse en aguas pantanosas con las manos atadas a la espalda.

La crítica feminista ha estado (y sigue estando, ocasionalmente) dominada por una moda historiográfica que en su día sostenía que «podría utilizarse prácticamente cualquier film de Hollywood para mostrar cómo se ha relegado a las mujeres al silencio, la ausencia o la marginalidad mediante el 
poder dominador de la mirada masculina». ${ }^{22}$ Sin embargo, ésta es una visión polarizada que sólo contempla la mitad del problema. ¿Qué ocurre cuando se ridiculiza 0 , al menos, se cuestiona dicha mirada desde el propio seno del clasicismo de Hollywood?

Y es que, en mi opinión, urge una relectura del cine clásico libre de los prejuicios del pasado. El análisis pormenorizado del mayor número posible de películas clásicas ofrecerá, sin duda alguna, una visión más completa del fenómeno y más ajustada a la realidad histórica. Y la relectura implica inevitablemente una reescritura de la historia del cine clásico y, con ello, de la propia Historia del Cine. Lo contrario supondrá ahogarse en aguas estancadas que cada vez huelen peor. Con todo, considero que toda revisión, toda reescritura, debe hacerse con la humildad que supone saber que una nueva "verdad" no sustituye a una "verdad" caduca sino que, todo lo más, se aportan nuevos matices a una visión sobre el objeto de estudio que cada vez será más rica y más comprensiva.

La responsabilidad del cambio es nuestra.

22 KAPLAN, E. Ann (1998), Las mujeres y el cine. A ambos lados de la cámara, Madrid, Cátedra, p. 73. El texto original fue publicado en inglés en 1983. 